\title{
Awareness of Chronic Kidney Disease among Patients Attending Tertiary Care Hospital in Bangladesh
}

\author{
Ferdous Jahan ${ }^{1 *}$, A. K. M. Shahidur Rahman1, Tania Mahbub², Mesbah Uddin Noman ${ }^{3}$, \\ Yeasmin Akter $^{4}$, Mohammed Mizanur Rahaman' ${ }^{5}$, K. B. M. Hadiuzzamann', M. A. Jalil Chowdhury ${ }^{6}$ \\ ${ }^{1}$ Department of Nephrology, Bangabandhu Sheikh Mujib Medical University (BSMMU), Dhaka, Bangladesh \\ ${ }^{2}$ Department of Nephrology, United Hospital Limited, Dhaka, Bangladesh \\ ${ }^{3}$ Department of Nephrology, M Abdur Rahim Medical College, Dinajpur, Bangladesh \\ ${ }^{4}$ Department of Gynecology and Obstetrics, Combined Military Hospital (CMH), Dhaka, Bangladesh \\ ${ }^{5}$ Department of Cardiology, Narail Sadar Hospital, Narail, Bangladesh \\ ${ }^{6}$ Department of Medicine, Bangabandhu Sheikh Mujib Medical University (BSMMU), Dhaka, Bangladesh \\ Email: *ferdousjahan1999@gmail.com
}

How to cite this paper: Jahan, F., Rahman, A.K.M.S., Mahbub, T., Noman, M.U., Akter, Y., Rahaman, M.M., Hadiuzzaman, K.B.M. and Chowdhury, M.A.J. (2019) Awareness of Chronic Kidney Disease among Patients Attending Tertiary Care Hospital in Bangladesh. Journal of Biosciences and Medicines, 7, 106-118.

https://doi.org/10.4236/jbm.2019.78009

Received: July 22, 2019

Accepted: August 27, 2019

Published: August 30, 2019

Copyright $\odot 2019$ by author(s) and Scientific Research Publishing Inc. This work is licensed under the Creative Commons Attribution International License (CC BY 4.0).

http://creativecommons.org/licenses/by/4.0/ (c) (i) Open Access

\begin{abstract}
Background: Patients with chronic kidney disease (CKD) are at increased risk of morbidity \& mortality. Educational interventions aimed at empowering patients are successful in chronic disease management including CKD. Objective: To explore the awareness regarding CKD among patients attending in a tertiary care hospital in Bangladesh. Methodology: This was a descriptive observational study, which includes 100 adult patients attending the department of Medicine in Bangabandhu Sheikh Mujib Medical University (BSMMU), Dhaka, Bangladesh from January 2013 to June 2013. Data were collected on a pre-tested questionnaire by face-to-face interview to investigate awareness toward: 1) basic knowledge of personal health; 2) perceptions of factors increasing the risk of CKD; 3) knowledge of therapies to slow CKD progression; 4) perceptions of CKD increasing the risk of other medical conditions and 5) demographic information. Main outcome variables were demographic parameters, socio-economic status and awareness about chronic kidney disease. Data were analyzed and compared by statistical tests. Results: Almost one third (32.0\%) respondents were in $3^{\text {rd }}$ decade and male to female ratio was $1: 1.5$. Majority (43.0\%) patients came from lower-middle income family. In all age groups, the majority (60\%) respondents had low knowledge of CKD. Among the study population, $44.0 \%$ believe that smoking increases risk of CKD; $42.0 \%$ believe that restricting salt intake reduces the progression of CKD; $34.0 \%$ mention that CKD increases the risk for hypertension and $82.0 \%$ mention that renal transplantation is the treatment of choice in CKD.
\end{abstract}


Among the participants, $32.8 \%$ had knowledge of increasing risk factor of CKD, 30.8\% had knowledge of the method of slow progression of CKD, $30.3 \%$ had knowledge of conditions for increase risk of CKD and $41.7 \%$ respondent had knowledge of treatment of CKD. Conclusion: Most of the study participants had inadequate knowledge of CKD. Lack of CKD screening and educational programs have contributed to the inadequate patient knowledge about the condition.

\section{Keywords}

Awareness, Chronic Kidney Disease, Patient Knowledge, Patient Perception

\section{Introduction}

Chronic kidney disease (CKD) is increasingly being recognized as a global public health problem. The declaration of World Kidney Day and its annual observance remained us that CKD is common and harmful for almost all cross section of people [1]. There is some convincing evidence that CKD is treatable [2]. Prevalence of CKD has reached epidemic proportions with a range of 10\% - 13\% population of USA [3], Canada [4], Japan [5], China [6], Taiwan [7], Iran [8], and India [9]. In some countries of Europe, the prevalence of CKD is $8 \%-10 \%$ [10] [11]. Recent data on the prevalence of early stage of CKD in India showed that $15 \%$ apparently healthy-looking Indian Central government employees are suffering from kidney disease [9].

As CKD is a silent disease which is treated as one of the leading causes of death worldwide, many developed countries have studied CKD awareness and developed guidelines and educational programs accordingly. Education to improve knowledge on CKD has been documented to play an important role in reducing this particular problem regardless of whether it is primary, secondary or tertiary prevention [12]. Varied risk factors have been reported in the awareness study on chronic kidney disease in different countries.

Bangladesh being a densely populated developing country, its health care budget is only $1.4 \%$ of gross national product (GNP) with the priority areas as population control, provision of clean drinking water and eradication of communicable disease. The treatment of non-communicable disease like chronic kidney disease (CKD) has low priority in Bangladesh because of government health policy and high cost of treatment [13]. Development of awareness through screening and educational programs is still in the stage of infancy. The important causes of CKD leading to kidney failure in South Asian region are chronic glomerulonephritis, diabetes and hypertension [13]. In Bangladesh, leading causes of end-stage renal disease (ESRD) are chronic glomerulonephritis (40\%), diabetes (34\%) and hypertension (15\%) [14]. Patients are not aware of the importance of good control of these risk factors. Survey in a few rural, urban, disadvantageous population suggested that 18 million people have been suffering 
from CKD as defined by kidney disease outcomes quality initiative (KDOQI) in Bangladesh [14]. About 30,000 patients are reaching end-stage renal failure every year in this country they need either dialysis or transplantation of kidney [14]. Out of $18 \%$ kidney patient, $11 \%$ have milder to severe form of kidney failure [14]. Increased CKD awareness over time in different countries and a recent increase in nephrology referrals suggested that these efforts may have some positive impact [15] [16] [17].

It has been observed that physicians other than nephrologists are less likely to recognize CKD and sometimes differ in their clinical evaluation of CKD [18]. A significant number of CKD patients are referred to nephrologists much later than it would have been appropriate [19]. Late evaluation of CKD patients by nephrologists, especially those presenting in end-stage renal disease (ESRD), is associated with suboptimal pre-dialysis care and treatment which ultimately increase mortality [19] [20] [21] [22].

Cancer screening studies have shown that patients with more knowledge and awareness of their diseases are more likely to follow methods that slow progression of the disease [23]. Disease educated patients are more likely to follow proper treatment and cope more successfully with their diagnosis and participate in health care decisions that affect their health [24].

Study on awareness and education of CKD is scarce in Bangladesh. Thus the present study was conducted to explore the awareness regarding CKD among patients attending in a tertiary care hospital in Bangladesh. The study was focused on the relationship between the awareness of CKD with age, occupation and educational status. The information generated out of this study will be useful in implying awareness program for CKD patients. The developed awareness program of the present study is expected to reduce CKD through early adoption of treatment and thereby will contribute to a considerable extent to prevent it from progression towards ESRD.

\section{Methodology}

This descriptive observational study was conducted from January 2013 to June 2013 in Bangabandhu Sheikh Mujib Medical University (BSMMU), Dhaka, Bangladesh. The study was approved by the Ethical Review Committee, Bangabandhu Sheikh Mujib Medical University (BSMMU) Dhaka, Bangladesh. According to the statistical calculation, a total of one hundred (100) patients were selected as study population. Patients who came to the department of medicine, BSMMU during six months of the study period were recruited for the study purposively. All adult (Age $>18$ years) patients without renal disease were included in the study and patients under 18 years old, known as CKD patient, CKD on dialysis or history of renal transplantation were excluded from the study. Informed written consent was taken from each participant prior to enrollment. Main outcome variables were demographic parameters, socio-economic status and awareness about chronic kidney disease. Data were collected by 
face-to-face interview using a pre-tested questionnaire. The questionnaire consisted of five sectors that included; demographic characteristics, patient's knowledge on health, patient's perceptions of factors increasing the risk of CKD, patient's perception of practices that slow chronic kidney disease progression and patient's perception of $\mathrm{CKD}$ increasing the risk of other medical conditions. Each of the patient's correct answer was given a score of 1 and therefore the maximum total score was 11 . Knowledge scouring was leveled as; no knowledge $=0$ score, low knowledge $=1-5$, moderate knowledge $=6-9$ and high knowledge $=9$ - 11 score. Those who answered 5 or fewer questions correctly were considered to have low knowledge on chronic kidney disease while those who answered 6-8 questions correctly were considered to have moderate knowledge while those who answered 9 - 11 questions correctly were considered to have high knowledge on CKD. After editing and coding, the coded data were directly entered into the computer by using SPSS software release for Windows, version 16.0 (SPSS, Inc. Chicago. III). Data cleaning validation and analysis were performed using the SPSS software. Categorical data were presented as frequency, percentage and continuous variable were expressed as mean \pm SD (standard deviation). An independent sample student's t-test was used for comparison of means of continuous variables with normal or approximately normal distributions. The Chi-square test was used to analyze discrete variables. ANOVA test was performed where appropriate. The statistical significance threshold was set to $\mathrm{p} \leq 0.05$ (two-tailed).

\section{Results}

A total of one hundred (100) participants were included in this study. Of them, forty (40) were male and sixty (60) were female, among females most of them were housewives and male to female ratio was $1: 1.5$. Almost one third $(32.0 \%)$ respondents were in $3^{\text {rd }}$ decade. Majority $(43.0 \%)$ patients came from lowermiddle-income family. In all age groups, the majority (60\%) respondents had low knowledge of CKD.

About the association between knowledge score with different age group, it was observed that majority patients $(60 \%)$ had low knowledge score which was $9.0 \%$ in $\leq 20$ years age group, $21.0 \%$ in 21 - 30 years age group, $16.0 \%$ in $31-40$ years age group, $10.0 \%$ in 41 - 50 years age group and $4.0 \%$ in $>50$ years age group patients. The mean knowledge score was found $4.75 \pm 4.47$ in $\leq 20$ years age group, $5.09 \pm 5.93$ in 21 - 30 years age group, $5.73 \pm 5.65$ in 31 - 40 years age group, $8.62 \pm 6.81$ in $41-50$ years age group and $7.11 \pm 8.79$ in $>50$ years age group. The differences were not statistically significant $(\mathrm{p}=0.240)$ among knowledge scoring with different age groups (Table 1).

Among the participants no knowledge score was found $1(2.5 \%)$ in male patients and $7(11.7 \%)$ in female patients; Low knowledge score was found 25 $(62.5 \%)$ in male patients, $35(58.3 \%)$ in female patients; Moderate knowledge score was found $9(22.5 \%)$ in male patients and $12(20.0 \%)$ in female patients; 
Table 1. Distribution of the study patients by knowledge score according to age group $(\mathrm{n}=100)$.

\begin{tabular}{|c|c|c|c|c|c|c|c|c|c|c|}
\hline \multirow{3}{*}{ Knowledge score } & \multicolumn{10}{|c|}{ Age (years) } \\
\hline & \multicolumn{2}{|c|}{$\begin{array}{c}\leq 20 \\
(n=12)\end{array}$} & \multicolumn{2}{|c|}{$\begin{array}{c}21-30 \\
(n=32)\end{array}$} & \multicolumn{2}{|c|}{$\begin{array}{c}31-40 \\
(n=23)\end{array}$} & \multicolumn{2}{|c|}{$\begin{array}{c}41-50 \\
(n=24)\end{array}$} & \multicolumn{2}{|c|}{$\begin{array}{c}>50 \\
(n=9)\end{array}$} \\
\hline & $\mathbf{n}$ & $\%$ & $\mathrm{n}$ & $\%$ & $\mathbf{N}$ & $\%$ & $\mathbf{N}$ & $\%$ & & \\
\hline No Knowledge & 0 & 0.0 & 3 & 3.0 & 1 & 1.0 & 2 & 2.0 & 2 & 2.0 \\
\hline Low Knowledge & 9 & 9.0 & 21 & 21.0 & 16 & 16.0 & 10 & 10.0 & 3 & 4.0 \\
\hline Moderate Knowledge & 3 & 3.0 & 4 & 4.0 & 6 & 6.0 & 8 & 8.0 & 0 & 0.0 \\
\hline High Knowledge & 0 & 0.0 & 4 & 4.0 & 0 & 0.0 & 3 & 4.0 & 3 & 3.0 \\
\hline Mean \pm SD & 4.75 & \pm 4.47 & 5.09 & \pm 5.93 & 5.73 & \pm 5.65 & 8.62 & \pm 6.81 & 7.11 & \pm 8.79 \\
\hline$P$ value & \multicolumn{10}{|c|}{$0.240^{\mathrm{ns}}$} \\
\hline
\end{tabular}

No knowledge $=0$. Low knowledge $=1-5$. Moderate knowledge $=6-9$. High knowledge $=9-11$. ns $=$ not significant. $\mathrm{P}$ value reached from ANOVA test.

High knowledge score was found $5(12.5 \%)$ in male patients and $6(10.0 \%)$ in female patients respectively. The mean knowledge score was found $6.5 \pm 6.7$ in male patients and $6.0 \pm 5.9$ in female patients. The mean score difference was not statistically significant ( $\mathrm{p}>0.05$ ) between two groups (Table 2 ).

In this study no knowledge score 4 (4\%), 1 (1\%), 1 (1\%), 0 (0\%), 1 (1\%), 0 (0\%); low knowledge score 17 (17\%), 8 (8\%), 5 (5\%), $10(10 \%), 4(4 \%), 6(6 \%)$; moderate knowledge score 11 (11\%), $9(9 \%), 5(5 \%), 5(5 \%), 2(2 \%), 0(0 \%)$ and high knowledge score $4(4 \%), 0(0 \%), 3(3 \%), 2(2 \%), 0(0 \%), 2$ (2\%) were found among housewives, small trader, student, service holder, private service and other occupation's patients respectively (Table 3 ). Among the occupations majority of the respondents were housewives (17\%) and they had low knowledge score.

Table 4 shows monthly income of the respondents. It was observed that more than two third (67.0\%) respondents belonged to lower-middle-income group and rest one third (33.0\%) came from low-income group (Table 4).

Low knowledge score was found in $10(10.0 \%)$ of the respondents who had no institutional education, in 17 (17.0\%) had primary education, in 15 (15.0\%) had high school education and in $18(18.0 \%)$ respondents who had college \& university-level education. Other knowledge scores and educational status are displaying in the table. But the mean differences were not statistically significant $(\mathrm{p}=0.071)$ among knowledge scores with different education groups (Table 5).

It was observed that $31(31.0 \%)$ respondents mention that they believe diabetes increases the risk of CKD, 32 (32.0\%) hypertension, 12 (12.0\%) family history, 44 (44.0\%) smoking 39 (39.0\%) dyslipidemia and 39 (39.0\%) believe obesity increases the risk of CKD (Table 6).

It was observed that $35(35.0 \%)$ respondents mention that they believe stop smoking slows down the progression of CKD, 29 (29.0\%) control of HTN 27 (27.0\%) control of DM, 33 (33.0\%) control of LIPID, 42 (42.0\%) restricting salt 
Table 2. Distribution of the study patients by knowledge score according to sex $(n=100)$.

\begin{tabular}{cccccc}
\hline \multirow{2}{*}{ Knowledge score } & \multicolumn{2}{c}{ Male $(\mathbf{n}=\mathbf{4 0})$} & \multicolumn{2}{c}{ Female $(\mathrm{n}=60)$} & \multirow{2}{*}{ P-value } \\
\cline { 2 - 5 } & $\mathrm{N}$ & $\%$ & $\mathrm{~N}$ & $\%$ & \\
\hline No Knowledge & 1 & 2.5 & 7 & 11.7 & \\
Low Knowledge & 25 & 62.5 & 35 & 58.3 & \\
Moderate Knowledge & 9 & 22.5 & 12 & 20.0 & \\
High Knowledge & 5 & 12.5 & 6 & 10.0 & \\
Mean \pm SD & 6.5 & \pm 6.7 & 6.0 & \pm 5.9 & $0.704^{\mathrm{ns}}$ \\
\hline
\end{tabular}

ns $=$ not significant. $\mathrm{P}$ value reached from unpaired $\mathrm{t}$-test.

Table 3. Distribution of the study patients by knowledge score according to occupation $(\mathrm{n}=100)$.

\begin{tabular}{|c|c|c|c|c|c|c|c|c|c|c|c|c|}
\hline \multirow{3}{*}{ Knowledge score } & \multicolumn{12}{|c|}{ Occupational status } \\
\hline & \multicolumn{2}{|c|}{ Housewife } & \multicolumn{2}{|c|}{ Small trader } & \multicolumn{2}{|c|}{ Student } & \multicolumn{2}{|c|}{$\begin{array}{l}\text { Service } \\
\text { holder }\end{array}$} & \multicolumn{2}{|c|}{$\begin{array}{l}\text { Private } \\
\text { service }\end{array}$} & \multicolumn{2}{|c|}{ Others } \\
\hline & $\mathrm{N}$ & $\%$ & $\mathrm{n}$ & $\%$ & $\mathrm{n}$ & $\%$ & $\mathrm{~N}$ & $\%$ & $\mathrm{n}$ & $\%$ & $\mathrm{~N}$ & $\%$ \\
\hline No Knowledge & 3 & 4.0 & 1 & 1.0 & 1 & 1.0 & 0 & 0.0 & 1 & 1.0 & 0 & 0.0 \\
\hline Low Knowledge & 17 & 17.0 & 8 & 8.0 & 5 & 5.0 & 10 & 10.0 & 4 & 4.0 & 6 & 6.0 \\
\hline $\begin{array}{l}\text { Moderate } \\
\text { Knowledge }\end{array}$ & 11 & 11.0 & 9 & 9.0 & 5 & 5.0 & 5 & 5.0 & 2 & 2.0 & 0 & 0.0 \\
\hline High Knowledge & 3 & 4.0 & 0 & 0.0 & 3 & 3.0 & 2 & 2.0 & 0 & 0.0 & 2 & 2.0 \\
\hline Total & 36 & 36.0 & 18 & 18.0 & 14 & 14.0 & 17 & 17.0 & 7 & 7.0 & 8 & 8.0 \\
\hline
\end{tabular}

Table 4. Distribution of the respondents by monthly income $(n=100)$.

\begin{tabular}{ccc}
\hline Monthly income & Number of respondents & Percentage \\
\hline Low-income & 33 & 33.0 \\
Lower-middle & 67 & 67.0 \\
Upper-middle & 0 & 0.0
\end{tabular}

Table 5. Distribution of the study patients by knowledge score according to education $(\mathrm{n}=100)$.

\begin{tabular}{|c|c|c|c|c|c|c|c|c|}
\hline \multirow{3}{*}{ Knowledge score } & \multicolumn{8}{|c|}{ Educational status } \\
\hline & \multicolumn{2}{|c|}{$\begin{array}{l}\text { No education } \\
\quad(n=17)\end{array}$} & \multicolumn{2}{|c|}{$\begin{array}{l}\text { Primary } \\
(n=31)\end{array}$} & \multicolumn{2}{|c|}{$\begin{array}{l}\text { High school } \\
\qquad(\mathrm{n}=23)\end{array}$} & \multicolumn{2}{|c|}{$\begin{array}{c}\text { College \& } \\
\text { University } \\
(n=29)\end{array}$} \\
\hline & $\mathbf{N}$ & $\%$ & $\mathbf{N}$ & $\%$ & $\mathbf{N}$ & $\%$ & $\mathbf{N}$ & $\%$ \\
\hline No Knowledge & 5 & 5.0 & 3 & 3.0 & 0 & 0.0 & 0 & 0.0 \\
\hline Low Knowledge & 10 & 10.0 & 17 & 17.0 & 15 & 15.0 & 18 & 18.0 \\
\hline Moderate Knowledge & 2 & 2.0 & 8 & 8.0 & 3 & 4.0 & 7 & 7.0 \\
\hline High Knowledge & 0 & 0.0 & 3 & 3.0 & 3 & 4.0 & 3 & 4.0 \\
\hline Mean \pm SD & 2.81 & \pm 4.02 & 6.03 & \pm 6.00 & 7.56 & \pm 6.89 & 7.48 & \pm 6.64 \\
\hline$P$ value & \multicolumn{8}{|c|}{$0.071^{\mathrm{ns}}$} \\
\hline
\end{tabular}

$\mathrm{ns}=$ not significant. $\mathrm{P}$ value reached from ANOVA test. 
intake and $19(19.0 \%)$ respondents mention that they believe taking the drug regimen always slows down the progression of CKD (Table 7).

This study reveals that $82.0 \%$ of the participants believe that renal transplantation is the treatment of choice in CKD, 22.0\% knows about dialysis is a treatment option of CKD, and as $21.0 \%$ believe that CKD can be treated by drugs (Table 8).

Table 9 shows that $32.8 \%$ respondents believe that there are some factors that increase the risk of $\mathrm{CKD}, 30.8 \%$ know the issues that slow down the progression of CKD, $30.3 \%$ are aware of the conditions for increase of CKD, and $41.7 \%$ have knowledge about treatment of CKD.

Table 6. Participants believe that factor increases risk of CKD $(n=100)$.

\begin{tabular}{ccccccc}
\hline \multirow{2}{*}{$\begin{array}{c}\text { Factors increasing risk } \\
\text { of CKD }\end{array}$} & \multicolumn{2}{c}{ Yes } & \multicolumn{2}{c}{ No } & \multicolumn{2}{c}{ Don't know } \\
\cline { 2 - 7 } & $\mathbf{n}$ & $\%$ & $\mathrm{~N}$ & $\%$ & $\mathrm{~N}$ & $\%$ \\
\hline Diabetes & 31 & 31.0 & 15 & 15.0 & 54 & 54.0 \\
Hypertension & 32 & 32.0 & 13 & 13.0 & 55 & 55.0 \\
Family history of CKD & 12 & 12.0 & 15 & 15.0 & 73 & 73.0 \\
Smoking & 44 & 44.0 & 9 & 9.0 & 47 & 47.0 \\
Dyslipidemia & 39 & 39.0 & 11 & 11.0 & 50 & 50.0 \\
Obesity & 39 & 39.0 & 14 & 14.0 & 47 & 47.0 \\
\hline
\end{tabular}

${ }^{*}$ Multiple response.

Table 7. Knowledge regarding slow progression of CKD $(n=100)$.

\begin{tabular}{ccccccc}
\hline $\begin{array}{c}\text { Progression } \\
\text { of CKD }\end{array}$ & \multicolumn{2}{c}{ Yes } & \multicolumn{2}{c}{ No } & \multicolumn{2}{c}{ Don't know } \\
\cline { 2 - 7 } & $\mathbf{n}$ & $\%$ & $\mathrm{~N}$ & $\%$ & $\mathrm{~N}$ & $\%$ \\
\hline Stopping smoking & 35 & 35.0 & 9 & 9.0 & 56 & 56.0 \\
Controlling of HTN & 29 & 29.0 & 19 & 19.0 & 52 & 52.0 \\
Controlling of DM & 27 & 27.0 & 21 & 21.0 & 52 & 52.0 \\
Controlling of LIPID & 33 & 33.0 & 19 & 19.0 & 48 & 48.0 \\
Restricting salt intake & 42 & 42.0 & 13 & 13.0 & 45 & 45.0 \\
Taking the drug & 19 & 19.0 & 11 & 11.0 & 70 & 70.0 \\
regimen & & & & & & \\
\hline
\end{tabular}

${ }^{*}$ Multiple response.

Table 8. Knowledge regarding treatment of CKD $(n=100)$.

\begin{tabular}{ccccccc}
\hline \multirow{2}{*}{ Treatment knowledge* } & \multicolumn{2}{c}{ Yes } & \multicolumn{2}{c}{ No } & \multicolumn{2}{c}{ Don't know } \\
\cline { 2 - 7 } & $\mathbf{n}$ & $\%$ & $\mathbf{N}$ & $\%$ & $\mathbf{N}$ & $\%$ \\
\hline Drugs & 21 & 21.0 & 17 & 17.0 & 62 & 62.0 \\
Dialysis & 22 & 22.0 & 16 & 16.0 & 62 & 62.0 \\
Renal Transplantation & 82 & 82.0 & 1 & 1.0 & 17 & 17.0 \\
\hline
\end{tabular}

${ }^{\star}$ Multiple response. 
Table 9. Total level of knowledge about CKD.

\begin{tabular}{cc}
\hline Items of CKD & Total level of knowledge (\%) \\
\hline Factor increase risk of CKD & 32.8 \\
Methods slow progression of CKD & 30.8 \\
Condition for increase risk for CKD & 30.3 \\
About treatment knowledge of CKD & 41.7 \\
\hline
\end{tabular}

\section{Discussion}

This descriptive observational study was carried out with an aim to determine the level of knowledge about chronic kidney disease among patients attending in the department of medicine in Bangabandhu Sheikh Mujib Medical University (BSMMU) and to finding out the relationship between awareness of chronic kidney disease with age, occupation and educational status of the patients. A total of 100 patients who attended in the department of medicine in BSMMU from January 2013 to June 2013 were included in this study accordingly.

About the association between knowledge score with different age group it was observed that majority of the study patients $(60 \%)$ had low knowledge score which was $9.0 \%$ in $\leq 20$ years age group, $21.0 \%$ in 21 - 30 years age group, $16.0 \%$ in 31 - 40 years age group, $10.0 \%$ in 41 - 50 years age group and $4.0 \%$ in $>50$ years age group patients. The mean knowledge score differences were not statistically significant $(\mathrm{p}=0.240)$ among knowledge scores with different age groups in this current study. Leng C.W., et al. [25] showed majority of the respondents answered 3 to 5 questions correctly giving a mean score of $3.44 \pm 1.53$ and a median score of 3; Eighty (5.6\%) respondents had no knowledge of kidney disease; Of these 80 respondents, most of them were $>40$ years old (72.1\%). Tan A.U., et al. [26] reported that only younger age was independent predictors of overall knowledge score. The current study is consistent with these above studies.

In this present study, it was observed that majority (31.0\%) respondents were passed primary education level followed by $29.0 \%$ passed college \& University level, $23.0 \%$ passed high school and $16.0 \%$ respondents had no education level. Tan A.U., et al. [26] reported that nearly all participants (96\%) in their study had at least completed high school education. In another study, Leng C.W., et al. [25] observed that $40.7 \%$ and $37.6 \%$ had secondary level and above secondary level of education respectively. Erick W. [27] obtained that $70 \%$ of the participants had acquired formal education of less than high school level. This low level of education could account for the inadequate patient's knowledge. Studies documented that a high correlation between educational attainment and health outcomes, as educated patients are more likely to allow proper treatment and cope more successfully with their diagnosis and participate in health care decisions that affect their outcome.

In this present study, it was observed that $31.0 \%$ respondents mention that they believe diabetes increases the risk of CKD, 32.0\% hypertension, $12.0 \%$ fam- 
ily history of CKD, $44.0 \%$ smoking, 39.0\% dyslipidemia and 39.0\% believe obesity increases the risk of CKD. Majority of the participants thought that a family history of CKD increased the risk of CKD as reported by Erick W. [27]. The less commonly identified risk factors of CKD were smoking mentioned in $10 \%$ and $32.0 \%$ mentioned about diabetes in his study. In current study, only $32 \%$ of the participants believe that hypertension increases the risk of chronic kidney disease. This finding is especially relevant as prior survey which demonstrated that black populations are less likely to perceive themselves as being susceptible to end-stage renal disease yet hypertension is the leading cause of ESRD among blacks obtained by Sanne S. et al. [28]. Most of the participants believed that a family history of chronic kidney disease increases the risk for CKD but a previous study in the United States by Tan A.U., et al. [26] showed that although most chronic kidney disease patients had a family history of chronic renal failure, they did not believe that it predisposed to chronic kidney disease. Tan A.U., et al. [26] found in their study that hypertension $92.1 \%$ and diabetes $86 \%$ were the two risk factors that were perceived as increasing the risk of CKD for the largest proportion of their study participants. Other risk factors like obesity mentioned 79.9\%, family history of CKD 75.1\%, smoking 74.7\%, African American race $71.6 \%$, and male sex $59.0 \%$ were less commonly identified as CKD risk factors [26].

In this current study it was observed that $35.0 \%$ respondents mention that they believe stop smoking delay progression of CKD, 29.0\% control of HTN, $27.0 \%$ control of DM, $33.0 \%$ control of LIPID, $42.0 \%$ restricting salt intake and $19.0 \%$ respondents mention that they believe taking the CKD drug regimen always delay progression of CKD. Erick W. [27] showed most participants thought that drugs always slowed progression of the chronic kidney disease while the least likely to be identified as effective in slowing progression of CKD was smoking control (8.0\%).

In this study, it was observed that $34.0 \%$ respondents mention that they believe CKD increases risk for the hypertension, $31.0 \%$ heart attack, $26.0 \%$ stroke and $30.0 \%$ death. Erick W. [27] identified that $90 \%$ of the participants thought that CKD increases the risk of death but few thought that CKD increases the risk of hypertension, heart attack and stroke. The present study shows that the participants have very poor knowledge about complications and outcome of CKD.

In this present study, it was observed that, $82.0 \%$ of the participants believe that renal transplantation is the treatment of choice in CKD, 22.0\% knows about dialysis is a treatment option of CKD, and $21.0 \%$ believe that CKD can be treated by drugs. Leng C.W., et al. [25] found 79.4\% respondent knew that kidney transplant is the best treatment for end-stage renal disease. $61.7 \%$ knew that dialysis treatment can be carried out either at home or at a dialysis centre. The present study reveals that participants have very poor knowledge about treatment options of CKD patients.

It was observed in this study that no knowledge score was found in $2.5 \%$ in 
male patients and in $11.7 \%$ in female patients; low knowledge score was found $62.5 \%$ in male patients, $58.3 \%$ in female patients; moderate knowledge score was $22.5 \%$ and $20.0 \%$ in male and female respectively and high knowledge score was found $5(12.5 \%)$ in male patients and $6(10.0 \%)$ in female patients. The mean knowledge score was found $6.5 \pm 6.7$ in male patients and $6.0 \pm 5.9$ in female patients. The mean score difference was almost similar between male and female participants. This result differs from the findings of Turner S. et al. [29], who had observed that younger and female participants had greater knowledge and awareness of CKD.

Regarding the associations between knowledge score and educational status, it was observed in this current study that low knowledge score was found in $10.0 \%$ respondents who had no institutional education, in $17.0 \%$ had primary education, in $15.0 \%$ had high school education and in $18.0 \%$ participants had college \& university level education. But the differences were not statistically significant $(\mathrm{p}=0.071)$ among knowledge scores with different education groups. Gheewala, P.A et al. showed that CKD knowledge score increased with a higher level of education; which is not consistent with this current study [30].

Among the respondents, $32.8 \%$ respondent had knowledge about increase risk factor of CKD, 30.8\% had knowledge about the method of slow progression of $\mathrm{CKD}, 30.3 \%$ had knowledge about conditions for increase risk of CKD and $41.7 \%$ respondent had knowledge about treatment of CKD.

To summarize, the current study found that majority $(60 \%)$ of the participant patients had inadequate knowledge about chronic kidney disease. Most of the patients did not know all the risk factors, methods to slow progression and the complications of CKD. The inadequate knowledge about chronic kidney disease among the patients may be due to several factors which include illiteracy, lack of health screening program and inadequate education of patients about the condition. This could be due to inadequate mass media involvement.

\section{Conclusion}

This study was undertaken to explore the awareness regarding CKD among the patients attending in a tertiary care hospital. Most of the respondents were in $3^{\text {rd }}$ decade and female predominant and they were mostly housewife. Majority of the study participants had inadequate knowledge of CKD. Lack of CKD screening and educational programs have contributed to the inadequate patient knowledge about the condition.

\section{Conflicts of Interest}

The authors declare no conflicts of interest regarding the publication of this paper.

\section{Limitations of Study}

It was a single centre study with relatively small sample size. 


\section{Recommendations}

In this study, most of the patients had insufficient knowledge of CKD. The knowledge can be improved by arranging local and regional workshop, use of aids like posters and leaflets displayed in hospitals and by the use of local and national media (TV, newspapers, journals etc) to highlight the issues related to factor increase risk of CKD, method of slow progression of CKD, and management of chronic kidney disease.

\section{References}

[1] Levey, A.S., Andreoli, S.P., DuBose, T., Provenzano, R. and Collins, A.J. (2007) CKD: Common, Harmful, and Treatable-World Kidney Day 2007. American Journal of Kidney Diseases, 49, 175-179. https://doi.org/10.1053/j.ajkd.2006.12.013

[2] Kopple, J.D. (2001) National Kidney Foundation K/DOQI Clinical Practice Guidelines for Nutrition in Chronic Renal Failure. American Journal of Kidney Diseases, 37, S66-S70. https://doi.org/10.1053/ajkd.2001.20748

[3] Coresh, J., Selvin, E., Stevens, L.A., Manzi, J., Kusek, J.W., Eggers, P., Van Lente, F. and Levey, A.S. (2007) Prevalence of Chronic Kidney Disease in the United States. JAMA, 298, 2038-2047. https://doi.org/10.1001/jama.298.17.2038

[4] Hemmelgarn, B.R., Manns, B.J., Lloyd, A., James, M.T., Klarenbach, S., Quinn, R.R., Wiebe, N. and Tonelli, M. (2010) Alberta Kidney Disease Network. Relation between Kidney Function, Proteinuria, and Adverse Outcomes. JAMA, 303, 423-429. https://doi.org/10.1001/jama.2010.39

[5] Imai, E., Horio, M., Watanabe, T., Iseki, K., Yamagata, K., Hara, S., Ura, N., Kiyohara, Y., Moriyama, T., Ando, Y. and Fujimoto, S. (2009) Prevalence of Chronic Kidney Disease in the Japanese General Population. Clinical and Experimental Nephrology, 13, 621-630. https://doi.org/10.1007/s10157-009-0199-x

[6] Shan, Y., Zhang, Q., Liu, Z., Hu, X. and Liu, D. (2010) Prevalence and Risk Factors Associated with Chronic Kidney Disease in Adults over 40 Years: A Population Study from Central China. Nephrology, 15, 354-361.

https://doi.org/10.1111/j.1440-1797.2009.01249.x

[7] Wen, C.P., Cheng, T.Y., Tsai, M.K., Chang, Y.C., Chan, H.T., Tsai, S.P., Chiang, P.H., Hsu, C.C., Sung, P.K., Hsu, Y.H. and Wen, S.F. (2008) All-Cause Mortality Attributable to Chronic Kidney Disease: A Prospective Cohort Study Based on 462 293 Adults in Taiwan. The Lancet, 371, 2173-2182. https://doi.org/10.1016/S0140-6736(08)60952-6

[8] Safarinejad, M.R. (2009) The Epidemiology of Adult Chronic Kidney Disease in a Population-Based Study in Iran: Prevalence and Associated Risk Factors. Journal of Nephrology, 22, 99-108.

[9] Varma, P.P., Raman, D.K., Ramakrishnan, T.S., Singh, P. and Varma, A. (2010) Prevalence of Early Stages of Chronic Kidney Disease in Apparently Healthy Central Government Employees in India. Nephrology Dialysis Transplantation, 25, 3011-3017. https://doi.org/10.1093/ndt/gfq131

[10] Hallan, S.I., Coresh, J., Astor, B.C., Åsberg, A., Powe, N.R., Romundstad, S., Hallan, H.A., Lydersen, S. and Holmen, J. (2006) International Comparison of the Relationship of Chronic Kidney Disease Prevalence and ESRD Risk. Journal of the American Society of Nephrology, 17, 2275-2284.

https://doi.org/10.1681/ASN.2005121273

[11] Stevens, P.E., O’donoghue, D.J., De Lusignan, S., Van Vlymen, J., Klebe, B., Mid- 
dleton, R., Hague, N., New, J. and Farmer, C.K. (2007) Chronic Kidney Disease Management in the United Kingdom: NEOERICA Project Results. Kidney International, 72, 92-99. https://doi.org/10.1038/sj.ki.5002273

[12] Levin, A., Stevens, P.E., Bilous, R.W., Coresh, J., De Francisco, A.L., De Jong, P.E., Griffith, K.E., Hemmelgarn, B.R., Iseki, K., Lamb, E.J., Levey, A.S. and Kidney Disease: Improving Global Outcomes (KDIGO) CKD Work Group (2013) KDIGO 2012 Clinical Practice Guideline for the Evaluation and Management of Chronic Kidney Disease. Kidney International Supplements, 3, 1-150.

[13] Kidney Foundation (2005) Annual Reports. Dhaka.

[14] Rashid, H.U. (2011) Reports of President, 9th Conference of NUTS of SAARC Country.

[15] Plantinga, L.C., Boulware, L.E., Coresh, J., Stevens, L.A., Miller, E.R., Saran, R., Messer, K.L., Levey, A.S. and Powe, N.R. (2008) Patient Awareness of Chronic Kidney Disease: Trends and Predictors. Archives of Internal Medicine, 168, 2268-2275. https://doi.org/10.1001/archinte.168.20.2268

[16] Hemmelgarn, B.R., Zhang, J., Manns, B.J., James, M.T., Quinn, R.R., Ravani, P., Klarenbach, S.W., Culleton, B.F., Krause, R., Thorlacius, L. and Jain, A.K. (2010) Nephrology Visits and Health Care Resource Use before and after Reporting Estimated Glomerular Filtration Rate. JAMA, 303, 1151-1158.

https://doi.org/10.1001/jama.2010.303

[17] Saab, G., Whaley-Connell, A.T., McCullough, P.A. and Bakris, G.L. (2008) CKD Awareness in the United States: The Kidney Early Evaluation Program (KEEP). American Journal of Kidney Diseases, 52, 382-383. https://doi.org/10.1053/j.ajkd.2008.05.026

[18] Boulware, L.E., Troll, M.U., Jaar, B.G., Myers, D.I. and Powe, N.R. (2006) Identification and Referral of Patients with Progressive CKD: A National Study. American Journal of Kidney Diseases, 48, 192-204. https://doi.org/10.1053/j.ajkd.2006.04.073

[19] Gøransson, L.G. and Bergrem, H. (2001) Consequences of Late Referral of Patients with End-Stage Renal Disease. Journal of Internal Medicine, 250, 154-159. https://doi.org/10.1046/j.1365-2796.2001.00869.x

[20] Kinchen, K.S., Sadler, J., Fink, N., Brookmeyer, R., Klag, M.J., Levey, A.S. and Powe, N.R. (2002) The Timing of Specialist Evaluation in Chronic Kidney Disease and Mortality. Annals of Internal Medicine, 137, 479-486. https://doi.org/10.7326/0003-4819-137-6-200209170-00007

[21] Stack, A.G. (2003) Impact of Timing of Nephrology Referral and Pre-ESRD Care on Mortality Risk among New ESRD Patients in the United States. American Journal of Kidney Diseases, 41, 310-318. https://doi.org/10.1053/ajkd.2003.50038

[22] Chan, M.R., Dall, A.T., Fletcher, K.E., Lu, N. and Trivedi, H. (2007) Outcomes in Patients with Chronic Kidney Disease Referred Late to Nephrologists: A Meta-Analysis. The American Journal of Medicine, 120, 1063-1070. https://doi.org/10.1016/j.amjmed.2007.04.024

[23] Ueland, A.S., Hornung, P.A. and Greenwald, B. (2006) Colorectal Cancer Prevention and Screening: A Health Belief Model-Based Research Study to Increase Disease Awareness. Gastroenterology Nursing. The Official Journal of the Society of Gastroenterology Nurses and Associates, 29, 357-363. https://doi.org/10.1097/00001610-200609000-00002

[24] Swartz, M.D., Robinson, K., Davy, T. and Politoski, G. (1999) The Role of Patients in the Implementation of the National Kidney Foundation-Dialysis Outcomes Quality Initiative. Advances in Renal Replacement Therapy, 6, 52-58. 
https://doi.org/10.1016/S1073-4449(99)70008-7

[25] Chow, W.L., Joshi, V.D., Tin, A.S., van der Erf, S., Lim, J.F., Swah, T.S., Teo, S.S., Goh, P.S., Tan, G.C., Lim, C. and Kee, T.Y. (2012) Limited Knowledge of Chronic Kidney Disease among Primary Care Patients-A Cross-Sectional Survey. BMC Nephrology, 13, 54. https://doi.org/10.1186/1471-2369-13-54

[26] Tan, A.U., Hoffman, B. and Rosas, S.E. (2010) Patient Perception of Risk Factors Associated with Chronic Kidney Disease Morbidity and Mortality. Ethnicity \& Disease, 20, 106-110.

[27] Erick, W. (2012) Chronic Kidney Disease Knowledge among Patients in the Nephrology Unit at Mulago Hospital, Uganda. MMJ Original Research Article, 1-6.

[28] Sanne, S., Muntner, P., Kawasaki, L., Hyre, A. and DeSalvo, K.B. (2008) Hypertension Knowledge among Patients from an Urban Clinic. Ethnicity and Disease, 18, 42. https://doi.org/10.1097/00042871-200701010-00915

[29] Turner, S., Iliffe, S., Downs, M., Wilcock, J., Bryans, M., Levin, E., Keady, J. and O'Carroll, R. (2004) General Practitioners' Knowledge, Confidence and Attitudes in the Diagnosis and Management of Dementia. Age and Ageing, 33, 461-467.

https://doi.org/10.1093/ageing/afh140

[30] Gheewala, P.A., Peterson, G.M., Zaidi, S.T., Jose, M.D. and Castelino, R.L. (2018) Public Knowledge of Chronic Kidney Disease Evaluated Using a Validated Questionnaire: A Cross-Sectional Study. BMC Public Health, 18, 371.

https://doi.org/10.1186/s12889-018-5301-4 